\title{
New Car Demand Modeling and Forecasting Using Bass Diffusion Model
}

\author{
Zuhaimy Ismail and Noratikah Abu \\ Department of Mathematical Sciences, Faculty of Science, \\ Universiti Teknologi Malaysia, 81310 UTM Skudai, Johor Darul Takzim, Malaysia
}

Received 2013-02-08, Revised 2013-02-28; Accepted 2013-06-03

\begin{abstract}
Forecasting model of new product demand has been developed and applied to forecast new vehicle demand in Malaysia. Since the publication of the Bass model in 1969, innovation of new diffusion theory has sparked considerable research among marketing science scholars, operational researchers and mathematicians. The building of Bass diffusion model for forecasting new product within the Malaysian society is presented in this study. The proposed model represents the spread level of new Proton car among a given set of the society in terms of a simple mathematical function that elapsed since the introduction of the new car. With the limited amount of data available for the new car, a robust Bass model was developed to forecast the sales volume. A procedure of the proposed diffusion model was designed and the parameters were estimated. Results obtained by applying the proposed model and numerical calculation shows that the proposed diffusion model is robust and effective for forecasting demand of new Proton car. The proposed diffusion model is shown to forecast more effectively and accurately even with insufficient previous data on the new product.
\end{abstract}

Keywords: Bass Diffusion Model, Forecasting, New Product, Forecast Accuracy

\section{INTRODUCTION}

Demand forecasting is an iterative process for estimating the quantity of a product or services that the customer will purchase or consume. Many approaches are in demand forecasting which include the formal and informal method of forecasting. Demand forecasting may be used for making pricing decisions, for assessing the future capacity requirements, or for making decisions on whether to implement new power plant for the new township development. It is essential for companies in particular enable it to produce the required quantities at the right time and arrange well in advance for the various elements in the production processes.

Forecasting of new product demand is a process that determines a reasonable estimate of sales attainable under a given set of conditions. New product can mean different things to different people. When dealing with the new product demand, there are some problems that must be considered. First, new product forecasting has low credibility and low accuracy level due to the lack of or no historical data but only based on certain assumptions. Secondly, the time needed to develop forecast of new product is longer because it requires more manual and continuous attention. Lastly, data uncertainty and data scarcity occurred when it comes to new product.

During the last few decades, many studies have been carried out on demand forecasting but only a few has been done on forecasting of new product demand among the researchers. New product forecasting serves as a reality check by providing visibility to what is likely to happen. The new product demand forecasting is expected to be useful for company producing new product to know better the performance of their product and take action on any in coincidences. In this study, we focus on new product demand forecasting which receives less attention among the researchers. This study is organized as follows. Section 2 presents material and methods. The case study,

Corresponding Author: Zuhaimy Ismail, Department of Mathematical Sciences, Faculty of Science, Universiti Teknologi Malaysia, 81310 UTM Skudai, Johor Darul Takzim, Malaysia 
data and results analysis are presented in Section 3. Final comments in Section 4 conclude the study.

\subsection{Literature Review}

\subsubsection{Bass Diffusion Model}

Diffusion is the process by which an innovation is communicated through certain channels over time among the members of the social system. Mahajan and Muller (1979), stated in their research on innovation diffusion and new product growth models in marketing that the objective of diffusion model is to represent the level of spread of an innovation among given set of prospective adopters over time. The purpose of the model is to depict the successive increases in the numbers of adopters and predict the continued development of a diffusion process which already in progress. Innovative models of diffusion focus on communications external to the social system such as advertising and personal selling (Fourt and Woodlock, 1960). The imitative models of diffusion focus on communications internal to the social system such as word of mouth reports and observation of other users (Fisher and Pry, 1971). The Bass model is by far the most common diffusion model used in marketing and it is a mixed model capturing both innovative and imitative effects. This model assumed that the potential adopters of an innovation are influenced by two types of channel communications. One factor is the adopters, who receive innovation from mass media and other external factors is the innovators. The adopters normally receive innovation from wordof-mouth and observation or other interpersonal factors are called imitators. In building Bass model, the basic assumption is that the probability of an initial purchase takes place at time $t$, given that no purchase has yet been made is a linear function of the number of previous buyers. The conceptual structure of Bass model is presented in Fig. 1.

As shown in Fig. 1, the new adopters include innovators and imitators. When the new product or technologies are introduced into the market, the number of innovators decreases because of the less potential innovators. On the other side, the imitators increase due to the word-of-mouth communications that give strong influence to the imitators when more users adopt the new product. Then, the internal influences increase the noncumulative adopters to a peak and then drops gradually as the market get saturated. Rui and Lan (2012), applied Bass diffusion model to forecast the number of mobile phone in China. In his paper, he estimates the trend of adoption of mobile phones using Bass diffusion model.

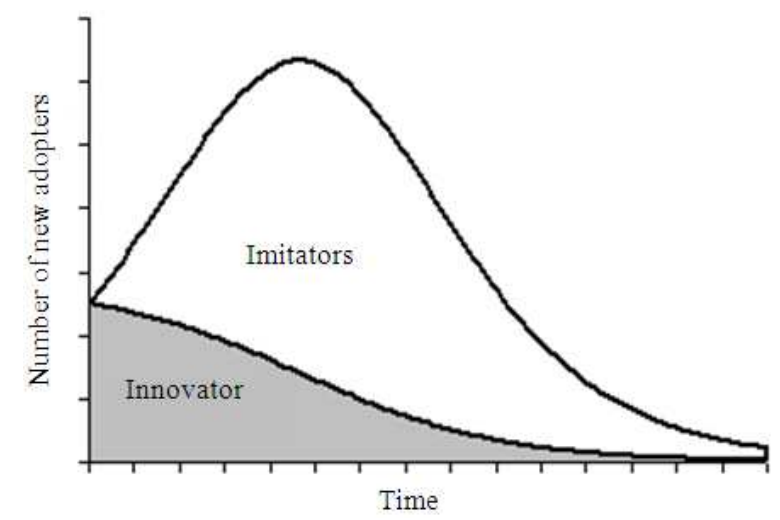

Fig. 1. Numbers of new adopters versus time

Result shows that Bass model is suitable for accurate fitting and forecasting the diffusion of mobile phones and also gives ultimate potential market that is $80-90 \%$ of the total population in China. It is a common practice when forecasting using quantitative analogies, where experts are asked to identify situations that are analogous to the target situation and for which the data are available. Kim et al. (2009), then applied basic Bass model to forecast the diffusion of new technology in a market and showed that the model can be used in new technology product forecasting. Radojicic and Markova (2009) also forecast demand for new technology product in television using the basic Bass model. They found that the model can be used to predict the peak sales of new product forecast and able to forecast the timing of the peak sales.

Since there are not many previous studies of Bass model on the new product vehicle demand forecasting, this study focus on developing bass model for forecasting new vehicle demand. The objective is to implement the basic Bass model in new product demand forecasting.

\section{MATERIALS AND METHODS}

Bass model was developed by Bass (1969) and widely used for new product forecasting. In this model, he said that when a new product was introduced, there are two potential users seeking information for the product. They are innovators which get the acquire information from the mass media and other external influences, while the imitative users get from interpersonal influence such as word-of-mouth communications and observation. The influence of these two types of users was used by Bass and comes out with the following theory of diffusion: 
"The probability that an initial purchase will be made at time $\mathrm{T}$ given that no purchase has yet been made is a linear function of the number of previous buyers"

Mathematically the model can be written as:

$$
P(t)=p+\left(\frac{q}{m}\right) Y(t)
$$

where, $\mathrm{P}(\mathrm{t})$ is the probability of purchase at time $\mathrm{t}, \mathrm{Y}(\mathrm{t})$ is the number of previous buyers, $\mathrm{m}$ is the total number of buyers, $p$ and $q$ are the coefficient of innovators and imitators, respectively. Then, after some algebraic process, Bass showed that the number of purchasing at time $t$ as:

$$
\mathrm{S}(\mathrm{t})=\mathrm{pm}+(\mathrm{q}-\mathrm{p}) \mathrm{Y}(\mathrm{t})-\frac{\mathrm{q}}{\mathrm{m}}(\mathrm{Y}(\mathrm{t}))^{2}
$$

where, $\mathrm{S}(\mathrm{t})$ is the sales at time $\mathrm{t}$ and $\mathrm{pm}$ is total number of buyer that initiate by innovators, $\mathrm{S}(0)=\mathrm{pm}$. The optimal time to peak sales and the size of peak sales are obtained by taking first derivatives of the bass model and from Bass, $t^{*}$ time to peak sales is given by:

$$
\mathrm{t}^{*}=\frac{\ln \frac{\mathrm{q}}{\mathrm{p}}}{\mathrm{p}+\mathrm{q}}
$$

Size of peak sales is given by:

$$
\mathrm{s}^{*}=\frac{\mathrm{m}(\mathrm{p}+\mathrm{q})^{2}}{4 \mathrm{q}}
$$

In Bass model diffusion, the accurate forecast can be achieved by estimating the parameters and in this model, the parameters are $\mathrm{p}$ (innovators), $\mathrm{q}$ (imitators) and $\mathrm{m}$ (potential users). In estimating parameters, from Bass (1969) an analogue is used:

$$
\mathrm{S}(\mathrm{t})=\mathrm{a}+\mathrm{bY}(\mathrm{t}-1)+\mathrm{c}(\mathrm{Y}(\mathrm{t}-1))^{2}, \mathrm{t}=2,3, \ldots
$$

where, $\mathrm{S}(\mathrm{t})$ is sales at time $\mathrm{t}, \mathrm{Y}(\mathrm{t}-1)$ is cumulative sales through period $\mathrm{t}-1$ and a estimates pm, b estimates (q-p) and c estimates $-\left(\frac{\mathrm{q}}{\mathrm{m}}\right)$. According to Mahajan and Muller (1979), there are two conditions when estimating parameters when predicting new product demand i.e., the availability of historical data and the non availability of historical data. Historical data is defined as not available when there are not more than three data are available. In such as case, the method employed is the management judgments and diffusion history of analogous products.
Historical data is defined as available when there are more than three data available and many methods can be used such as time-varying estimates and time-invariant estimates to name a few.

\subsection{Case Study}

The automobile industry plays an important role in all countries in the world. It is an important source of national income, a leading earning foreign exchange through exports and a supporting industry for labor and employment. Facing the strong market competition, many companies tend to decrease their overall cost while maintaining high customer satisfactions.

In Malaysia, one of the automobile industry organizations is Perusahan Otomobil Nasional Berhad (PROTON). Proton was incorporated in May 7, 1983 to manufacture, assemble and sell motor vehicles and related products, including accessories, spare parts and other components. PROTON produced the first Malaysian car, the Proton Saga, commercially launched on July 9, 1985 and since 1985 until now PROTON still produce new model like Saga, Waja, Perdana and many more. The latest model produced by PROTON is Inspira which was launched in November 2010. Inspira is classified in a new product category because Inspira is the latest model in the company and new model to the world. For this study, the sales data of PROTON cars were obtained from the Malaysian Automotive Association (MAA). The sales demand of Inspira increases from the time it was launched until present. As stated earlier, the purpose of this study is to study and apply the Bass model in new product forecasting. Hence, in our case, Inspira sales data are used in studying the Bass model.

\section{RESULTS AND DISCUSSION}

As discussed in Section 3 in Bass model, there are three parameters ( $\mathrm{p}, \mathrm{q}$ and $\mathrm{m}$ ) that are needed to estimate for forecasting purpose. Since Inspira has only one year data, from Mahajan and Muller, it can be categorized as a system with no historical data. Hence, we employ the comparative procedure with the similar product or technology in the same organization for estimating the parameters. Hence, we used the historical data for Proton Waja from 2002 until 2011 which is the similar product from PROTON and previous model before Inspira.

\subsection{Estimation Bass Model Parameters Using Regression Analysis by SPSS Software give the Results}

From Table 1, we can see that there are different values of parameters for different time series. For 
successful new product, the coefficient of imitation must be greater than innovation for the sales to achieve the maximum value at cumulative sales. So, we do not choose the parameters for the year 2002 until 2006. Since the value of imitation coefficient in year 2002 until 2011 and 2007 until 2011 are greater that innovation, we choose the 2002-2011 as the best parameters because of the highest adjusted $r$ square value. The $r$ square value indicates that the model describe the growth model well.

Figure 2 is the graphical representation of the probability of a customer's adoption of a new product over time; (a) shows the probability that a customer in the target segment will adopt the product before time $t$ and (b) shows the instantaneous likelihood that a customer will adopt the product at exactly time $t$.

Based on the parameters value, we can calculate the peak sales from Equation 1:

$$
\mathrm{S}(\mathrm{t})=\frac{\mathrm{m}(\mathrm{p}+\mathrm{q})^{2}}{4 \mathrm{q}}=\frac{(179242)(0.0503+0.484)^{2}}{4(0.484)}=26430
$$

And the time of peak sales:

$$
\mathrm{T}=\frac{\ln \left(\frac{\mathrm{q}}{\mathrm{p}}\right)}{\mathrm{p}+\mathrm{q}}=\frac{\ln \left(\frac{0.484}{0.0503}\right)}{(0.484+0.0503)}=4.24
$$

This shows that the time of peak sales will occur approximately in the 5th year after the product was launched. This result presented in the form of graph as in Fig. 3 and 4 demonstrates the findings.

Table 2 shows the comparison of actual and forecasted data of Inspira from 2011 until 2024. As we can see, the sales will achieve the maximum value at year 2016 and the sales will slowly drop as the markets get saturated.

Figure 3 and 4 gives the forecasting results obtained for cumulative sales and current sales Inspira using Bass model respectively. The results show that the comparison of the forecast value for 2011 and the actual value for 2011 is quiet accurate. From Bass (1969), he says that the growth of sales will increase to a peak and drops gradually as the market get saturated. From Fig. 4, it shows that, after the new product was launched in 2010, the sales will increase every each year and the peak sales was done in the year 2016. After that, the sales will slowly drops which means the new product reach its saturated state. From Fig. 3 and 4, it shows that our forecast on new product follows the Bass diffusion process as the pattern of the adoption follows the diffusion pattern on Fig. 2.
Table 1. Parameters value

\begin{tabular}{lllll}
\hline Waja & $\mathrm{m}$ & $\mathrm{P}$ & $\mathrm{Q}$ & r-square \\
\hline $2002-2011$ & 179242 & 0.0503 & 0.4840 & 0.92 \\
$2002-2006$ & 231538 & 0.1589 & 0.0903 & 0.67 \\
$2007-2011$ & 177740 & 0.0287 & 0.4266 & 0.84 \\
\hline
\end{tabular}

\begin{tabular}{|c|c|c|c|c|}
\hline Year & $\begin{array}{l}\text { Actual } \\
\text { sales } S(t)\end{array}$ & $\begin{array}{l}\text { Cumulative } \\
\text { sales } Y(\mathrm{t})\end{array}$ & $\begin{array}{l}\text { Forecasted } \\
\text { current sales } \\
\mathrm{S}(\mathrm{t})\end{array}$ & $\begin{array}{l}\text { Forecasted } \\
\text { cumulative } \\
\text { sales } Y(t)\end{array}$ \\
\hline 2011 & 8074 & 8074 & 9016 & 9016 \\
\hline 2012 & & & 12707 & 21723 \\
\hline 2013 & & & 17163 & 38886 \\
\hline 2014 & & & 21797 & 60683 \\
\hline 2015 & & & 25391 & 86074 \\
\hline 2016 & & & 26341 & 112415 \\
\hline 2017 & & & 23647 & 136062 \\
\hline 2018 & & & 18037 & 154099 \\
\hline 2019 & & & 11727 & 165826 \\
\hline 2020 & & & 6683 & 172509 \\
\hline 2021 & & & 3476 & 175985 \\
\hline 2022 & & & 1712 & 177697 \\
\hline 2023 & & & 819 & 178516 \\
\hline 2024 & & & 387 & 178903 \\
\hline
\end{tabular}

Table 2. Sales for parameters $(p=0.0503, q=0.4840)$

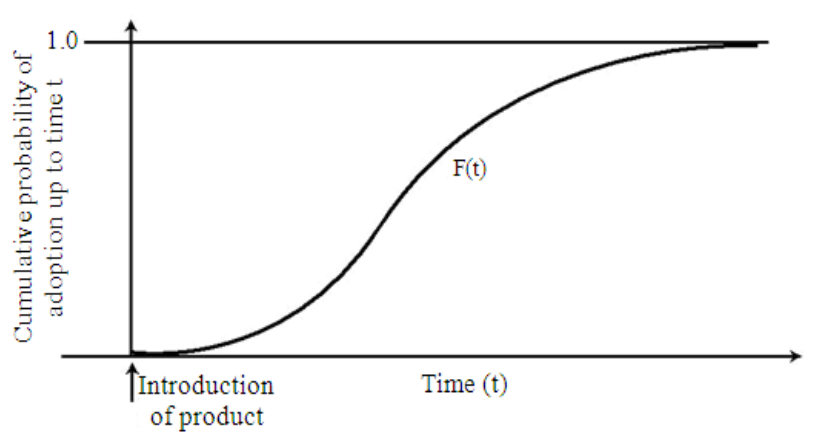

(a)

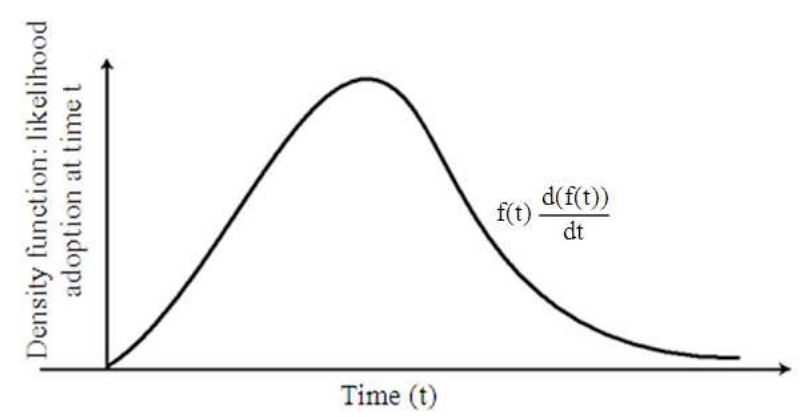

(b)

Fig. 2. The Bass new product diffusion model 


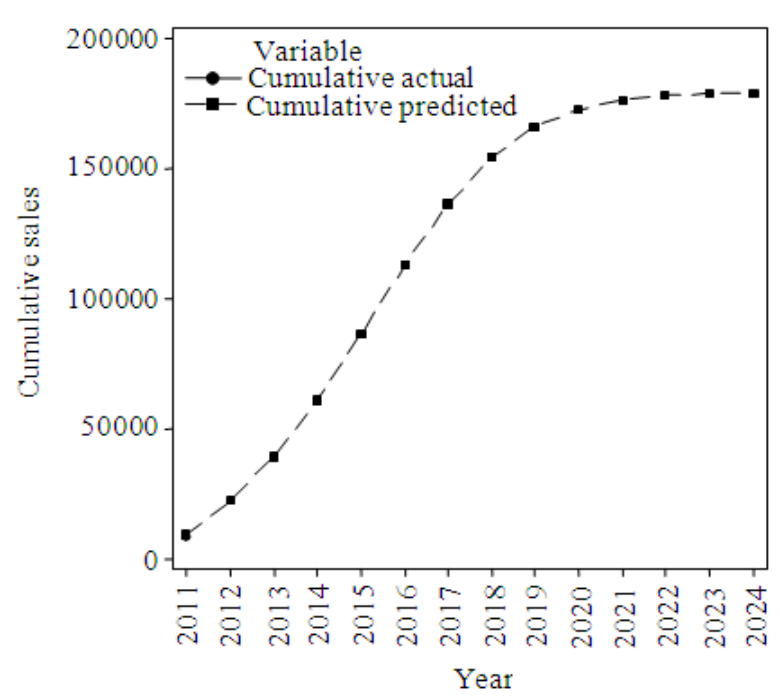

Fig. 3. Forecasting cumulative sales proton Inspira

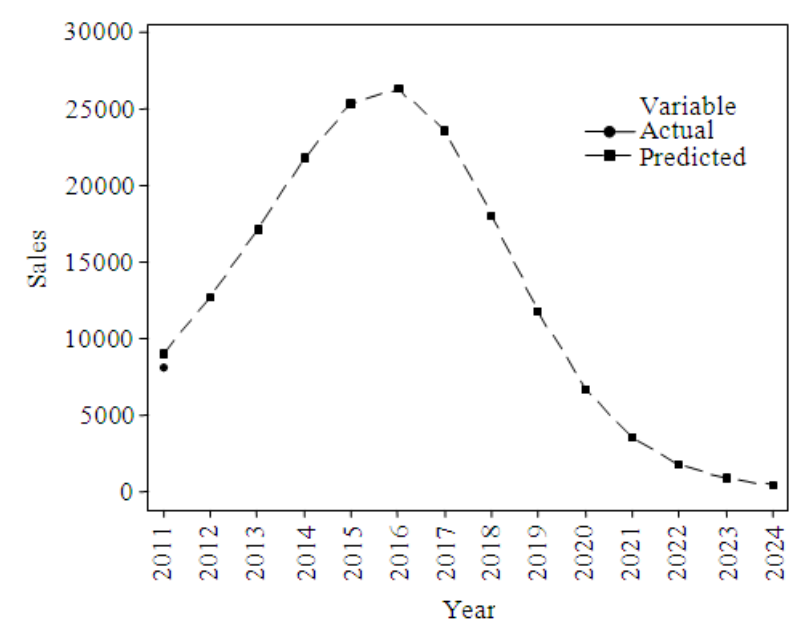

Fig. 4. Forecasting current sales proton Inspira

\section{CONCLUSION}

Bass diffusion model is a popular diffusion model in new product forecasting. This model have the ability to predict the number of adoptions and the timing of the peak sales, comparison of new adopters between actual and forecasted and forecasting the long term pattern of diffusion process. The Bass model is based on estimating three parameters namely the innovations, imitations and number of adopters. If these parameters are correctly estimated, an accurate forecast can be produced. This study studies the Bass diffusion model and applied the model for forecasting new product in vehicle demand in Malaysia. Results obtained, proved that the model can be applied in forecasting Proton Inspira even with no historical data are available. After Inspira was launched, the number of adopters increases every year and slowly decreases after the peak sales demand in 2016 .

In this study two main factors were considered namely the innovators and the imitators. Further works can be done to include other factors such as advertising, product knowledge and others. In the area of parameter estimations, new methods may be exploited using modern heuristic methods such as Neural Network (Ismail and Khamis, 2011) and show the behavior of the parameters in Bass model.

\section{ACKNOWLEDGMENT}

This research was supported by the Ministry of Higher Education (MOHE) under FRGS Grant Vot No. 77345 and the Department of Mathematics, Faculty of Science, Universiti Teknologi Malaysia. These supports are gratefully acknowledged. The authors would like to thank lecturers and friends for many helpful ideas and discussion.

\section{REFERENCES}

Bass, F.M., 1969. A new product growth for model consumer durables. J. Manage. Sci., 15: 215-227. DOI: $10.1287 / \mathrm{mnsc}$.15.5.215

Fisher, J.C. and R.H. Pry, 1971. A simple substitution model of technological change. Technol. Forecast. Soc. Change, 3: 75-88. DOI: 10.1016/S00401625(71)80005-7

Fourt, L.A. and J.W. Woodlock, 1960. Early prediction of market success for new grocery products. J. Market., 25: 31-38. DOI: 10.2307/1248608

Ismail, Z. and Z. Khamis, 2011, Neural network in modeling Malaysian oil palm yield. Am. J. Applied Sci., 8: 796-803. DOI: 10.3844/ajassp.2011.796.803

Kim, D.H., Y.G. Shin, S.S. Park and D.S. Jang, 2009. Forecasting diffusion of technology by using bass model. Proceedings of the International Conference on Computational Methods in Sciences and Engineering, Sep. 25-30, Hersonissos, Crete, Greece, pp: 149-152. DOI:10.1063/1.3225258

Mahajan, V. and E. Muller, 1979. Innovation diffusion and new product growth models in marketing. J. Market., 43: 55-68. DOI: 10.2307/1250271 
Radojicic, V. and G.Z. Markovic, 2009. New technology forecasting using the bass model. Proceedings of the 9th International Conference on Telecommunication in Modern Satellite, Cable and Broadcasting Services, Oct. 7-9, IEEE Xplore Press, Nis, pp: 277280. DOI: 10.1109 /TELSKS.2009.5339534
Rui, H. and K.S. Lan, 2012. Chai-na/China Signs. University of Pennsylvania and Slought Foundation. 